\title{
Post-Exposure Prophylaxis against HBV and HIV Infection in Health Care Workers
}

\author{
Azar Hadadi $^{{ }^{*}}$, Mojgan Karbakhsh ${ }^{2}$, Mehrnaz Rasoolinejad ${ }^{3}$, \\ Mahboobeh Haji Abdolbaghi ${ }^{3}$, Nahid Hadadi ${ }^{4}$, Shirin Afhami, \\ Negin Esmaeelpour-Bazzaz ${ }^{4}$
}

${ }^{1}$ Internal Medicine Ward, Sina Hospital, Tehran University of Medical Sciences, Tehran, Iran; ${ }^{2}$ Department of Community medicine, Faculty of medicine, Tehran University of Medical Sciences, Tehran, Iran; ${ }^{3}$ Department of Infectious Diseases, Imam Khomeini Hospital, Iranian Research Center for HIV/AIDS, Tehran University of Medical Sciences, Tehran, Iran; ${ }^{4}$ Shariati Hospital, Tehran University of Medical Sciences, Tehran, Iran.

Email: "hadadiaz@tums.ac.ir

Received April 20"th, 2013 ; accepted May 20 $0^{\text {th }}, 2013$; accepted June $20^{\text {th }}, 2013$

Copyright (C) 2013 Azar Hadadi et al. This is an open access article distributed under the Creative Commons Attribution License, which permits unrestricted use, distribution, and reproduction in any medium, provided the original work is properly cited.

\begin{abstract}
Healthcare Workers (HCWs) are constantly at risk of exposure to viral infections such as hepatitis B virus (HBV), human immune deficiency virus (HIV) and hepatitis C virus (HCV). We aim at demonstrating the results of a three-year period of a surveillance program in Iran with the prospective follow-up of HCWs exposed to blood-borne viruses. HCWs who had experienced an occupational exposure to HBV, HCV or HIV from September 2005 to 2008 were enrolled in the study. Age, gender, route of exposure, type of fluid, type of virus, job, department, working shift, work experience, wearing gloves when exposed, history of HBV vaccination and the serum level of anti HBs antibody were recorded for all participants through an individual interview. Serum samples were taken from both HCWs and the sources of exposure and were tested by enzyme linked immunosorbent assay (ELISA). The data were gathered through questionnaires completed by a nurse under the supervision of a specialist of infectious diseases. In this study, 100 HCWs who were occupationally exposed to HIV, HCV or HBV were included. Most exposures had occurred among nurses (35\%), followed by residents (29\%), interns (18\%), housekeepers (7\%), the lab staff (6\%), and specialists (5\%). Most of the exposures had occurred in emergency (21\%) and surgical (20\%) wards. The most common route of exposure was percutaneous injuries (77\%) and the most common cases had contacted with needles and angiocaths $(71.1 \%)$ during injection or opening vein routes (21\%). Establishing a surveillance system for registering the occurrence of occupational hazardous exposures, performing prophylactic measures and following up the exposed is a necessity in hospitals so that the number of exposures and occupational diseases among the HCWs can be decreased.
\end{abstract}

Keywords: Post-Exposure Prophylaxis; HBV Infection; HIV Infection; Health Care Workers

\section{Introduction}

Healthcare Workers (HCWs) are constantly at risk of exposure to viral infections such as hepatitis B virus (HBV), human immune deficiency virus (HIV) and hepatitis $\mathrm{C}$ virus (HCV) through percutaneous, mucosal and non-intact skin having contact with blood and other body fluids that are potentially infectious. Hepatitis B is a known occupational hazard for the HCWs [1]. Following occupational contacts of unvaccinated staff with the contaminated blood of an HBsAg positive patient; they should be followed by prophylactic measures including

${ }^{*}$ Corresponding author.
HBIG with vaccine. The efficacy of this method has been reported to be $85 \%$ - $95 \%$ in children born to HBsAg positive mothers, but it had not been sufficiently investigated in relation to HCWs [2,3]. Although, hepatitis B can be highly prevented through timely vaccinations, vaccination and check up for the antibody thereafter are not yet taken seriously by some HCWs.

Another occupational infection for HCWs is HIV with the risk of transferring through a needle stick and mucosal surfaces at $0.3 \%$ and $0.09 \%$, respectively. Following the contact with the infected blood, administering antiretroviral drugs such as Zidovudine plus Lamivudine with or without Nelfinavir within the first 4 hours, would be 
effective in preventing the infection in $81 \%$ of the cases [3]. These drugs are expensive and there may be the risk of creating resistant strains, so they should be cautiously used by consulting with a specialist of infectious diseases.

Hepatitis C is another blood borne infection that unfortunately has no appropriate immunoglubolin or vaccination. The prevalence of hepatitis $\mathrm{C}$ is $0.3 \%$ in Iran and the risk of infection through a needle stick is $1 \%-8 \%$ [1].

We aim at demonstrating the results of a three-year period of a surveillance program in Iran with the prospective follow-up of HCWs exposed to blood-borne viruses.

\section{Materials \& Methods}

Since the year 2005, a surveillance system has been established in HIV/AIDS Counseling center in Tehran University of Medical Sciences through which health care workers (HCWs) can report needle-stick injuries not only with HIV but also with HBV and HCV; they can ask for consultations on follow-up, as well. This study was designed to assess the profile of these clients regarding the setting in which exposures had occurred, the HBV vaccination status and the efficacy of the post-exposure prophylaxis for HIV and HBV. HCWs that had experienced an occupational exposure to HBV, HCV or HIV from September 2005 to 2008 were enrolled in the study. By HCWs, we mean physicians, medical students, nurses, the laboratory staff and housekeepers. Exposure refers to percutaneous injuries caused by needle stick and other sharp instruments and tools as well as contacts through mucosal surfaces and damaged skin (dermatitis or wound). Contaminants include blood, bloody secretions, CSF, pleural, peritoneal, synovial and pericardial fluids.

Pregnant women, people with chronic renal and hepatic diseases, immune deficiency syndromes and previous infections with these viruses on the basis of lab evidence were excluded.

Age, gender, route of exposure, type of fluid, type of virus, job, department, working shift, work experience, wearing gloves when exposed, history of HBV vaccinetion and the serum level of anti HBs antibody were recorded for all participants through an individual interview. If a HCW was unaware of the HBsAb level, it was tested.

Post-exposure measures:

Serum samples were taken from both HCWs and the sources of exposure and were tested by enzyme linked immunosorbent assay (ELISA) to detect HBsAg, HBsAb, HCVAb, and HIVAb. In source of positive serology of HIV, the samples were tested using ELISA two times and the samples positive for HIVAb ELISA were retested by Western Blot as a complementary test. The samples found positive with both ELISA and Western Blot HIVAb were considered to be infected by HIV. In cases of exposure to HBV with no previous vaccination or negative antibody despite previous vaccinations, HBIG and HBV intra-muscular vaccination in months 0 , 3 and 6 were administered and one month later (month 7), HBsAg and HBsAb titers were checked [2,3].

In case of HCV exposure, the ELISA Anti HCV Ab and liver function enzymes were checked 3 times ( 0,3 and 6 months after the exposure).

When there was an exposure to HIV, depending on the severity of the exposure (solid needle, being superficial or being infected by patients with an HIV viral load $<1500$ copies/ml to high risk injuries such as those resulting from hollow bore needles, presence of visible blood on the device, or exposure from a needle that was in an artery or vein of the source), two different protocols were used for 4 weeks prophylaxis: Zidovudine [ZDV] $(600 \mathrm{mg} / \mathrm{d})+$ Lamivudine [3TC] $(150 \mathrm{mg} / \mathrm{bd})$ for mild exposures and ZDV + 3TC + Nelfinavir (750 mg/tds) for severe exposures. During the follow-up period, the cases received some information on the effects of the drugs and were advised to apply preventive measures including condom use. HIVAb was checked 3 times during the follow-up period (6, 12 and 24 weeks after the exposure considering the window period) [3].

The efficacy of postexposure prophylaxis was considered as the main outcome of the study. It is defined as the rate or percentage of the decrease in the probability of HIV infection after prophylaxis (PEP). HIV seroconversion refers to the negative serum sample for HIVAb until one month after the exposure and its becoming positive during a six-month period after the exposure [4].

The data were gathered through questionnaires completed by a nurse under the supervision of a specialist of infectious diseases; the data were then analyzed using SPSS ver. 11.5. The mean and standard deviation were calculated for quantitative variables, and absolute and relative frequencies of categorical variables were computed for presenting the results.

Written informed consent was obtained from patients. The study was approved by the Ethics Committee of Tehran University of Medical Sciences.

\section{Results}

In this study, 100 HCWs who were occupationally exposed to HIV, HCV or HBV were included (Figure 1). The mean age of the exposed HCWs was $30.46 \pm 7.1$ (SD) years (range 20 - 56) and 54\% of them were female. Most exposures had occurred among nurses (35\%), followed by residents (29\%), interns (18\%), housekeepers (7\%), the lab staff (6\%), and specialists (5\%). Excluding the HCWs in training (residents and interns) the mean of the employment period was $6.5 \pm 6$ years; $75 \%$ had less 


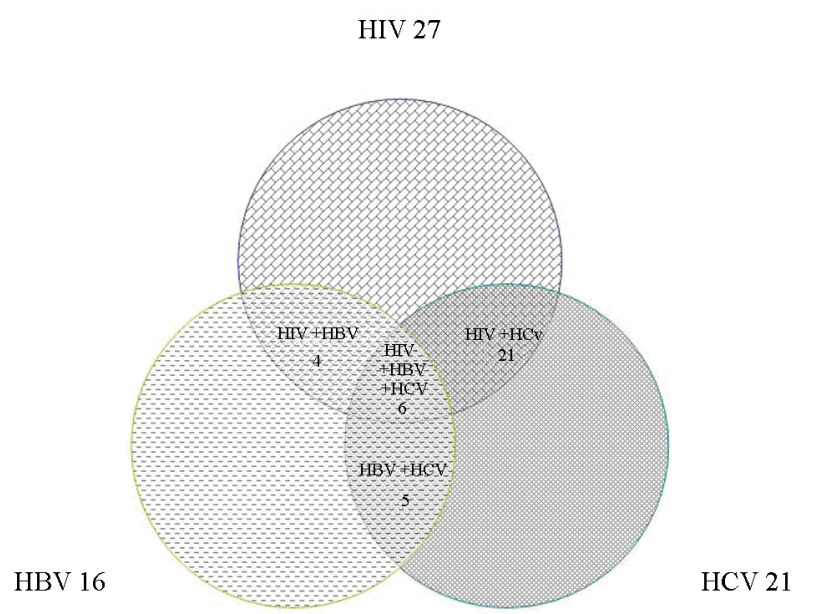

Figure 1. The contaminated of contact source with studied viruses.

than 5 years, 9\% between 5 and 10 years and 16\% had over 10 years of experience.

Table 1 shows exposure-related features. Most of the exposures had occurred in emergency (21\%) and surgical (20\%) wards. The most common route of exposure was percutaneous injuries (77\%) and the most common cases were having contact with needles and angiocaths (71.1\%) during injection or opening vein routes (21\%). The most common contaminant was blood (84\%). Most of the exposures had occurred during the morning work shifts (54\%) and then, the night shifts (25\%). Only 69\% of the exposed HCWs were using gloves at the time of their exposure.

The most common exposures among these personnel were to HIV (58 cases), followed by HCV (53 cases) and then HBV (31 cases). In 36 cases of exposure, the source was contaminated with more than one kind of virus; Figure 1 shows the prevalence of co-infection patterns among the source patients. Exposure-related features are also outlined by the type of viruses in Table 2 .

Ninety percent of the exposed HCWs $(n=90)$ had received at least one dose of $\mathrm{HBV}$ vaccine before their recent exposure; $5.5 \%$ of them had taken one dose ( $\mathrm{n}=$ 5), $8.8 \%$ two doses $(n=8)$ and $88.5 \%$ three doses of the vaccine. Based on personal declaration, the HBsAb was positive in $35 \%$ of the cases at the time of exposure, $9 \%$ had negative $\mathrm{HBsAb}$ and $56 \%$ did not know the status of their HBsAb.

Among $31 \mathrm{HCWs}$ who had exposure to HBV, twenty HCWs (64.5\%) had negative serology against HBV at the time of exposure (Table 3). No cases of seroconversion were observed among the $20 \mathrm{HCWs}$ exposed to HBV who had received prophylaxis (HBIG + vaccination); the level of antibody against HBV had risen in all of them seven months later.

There were 9 cases exposed to viruses other than HBV but they were found to be HBsAb negative; these sub-
Table 1. Exposure characteristics based on site of occurrence, type of device and cause of exposure.

\begin{tabular}{|c|c|c|}
\hline \multicolumn{2}{|c|}{ Exposure characteristics } & \multirow{2}{*}{$\begin{array}{c}\text { N (\%) } \\
77 \text { (77) }\end{array}$} \\
\hline \multirow{7}{*}{ Route of exposure } & Cutaneous & \\
\hline & Mucosal & $15(15)$ \\
\hline & Non intact skin & $18(18)$ \\
\hline & Emergency & $21(21)$ \\
\hline & Surgery & $20(20)$ \\
\hline & Orthopedics & $14(14)$ \\
\hline & Medical & $13(13)$ \\
\hline \multirow[t]{6}{*}{ Ward } & Intensive care & $12(12)$ \\
\hline & laboratory & $5(5)$ \\
\hline & hemodialysis & $5(5)$ \\
\hline & Infectious & $5(5)$ \\
\hline & Others & $5(5)$ \\
\hline & Blood & $84(84)$ \\
\hline \multirow[t]{3}{*}{ Contaminated substance } & Bloody fluids & $9(9)$ \\
\hline & $\begin{array}{c}\text { Other contaminated } \\
\text { substance }\end{array}$ & $7(7)$ \\
\hline & Injection needle & $59(71.1)$ \\
\hline \multirow{7}{*}{ Type of device } & Suture needle & $20(24.1)$ \\
\hline & Bistory & $4(4.8)$ \\
\hline & Total & $83(100)$ \\
\hline & Venous puncture & $21(21)$ \\
\hline & Splashing & $17(17)$ \\
\hline & Suturing & $17(17)$ \\
\hline & Recapping & $14(14)$ \\
\hline \multirow[t]{5}{*}{ Cause of contact } & Injection & $11(11)$ \\
\hline & Sweeping & $5(5)$ \\
\hline & Surgery & $5(5)$ \\
\hline & Needle Aspiration & $3(3)$ \\
\hline & Other causes & $7(7)$ \\
\hline
\end{tabular}

jects were given vaccinations.

No cases of seroconversion were observed among the HCWs exposed to HCV.

In 18 cases out of 58 exposures to HIV, the two-drug protocol (ZDV + 3TC) was used and in 40 cases, ZDV + 3TC + Nelfinavir was given based on the characteristics of exposure and the source patients. No case of seroconversion was seen among the study group during the six-month follow-up period.

\section{Discussion}

Some reports indicate that more than 3 million HCWs 
Table 2. Comparison of exposure characteristics based on different type of viruses.

\begin{tabular}{|c|c|c|c|c|}
\hline \multicolumn{2}{|c|}{ Exposure characteristics } & HCV N = 53 & $\mathrm{HBV} N=31$ & HIV N = 58 \\
\hline \multirow{3}{*}{ Route of exposure } & Cutaneous & 38 (71.7\%) & $23(74.2 \%)$ & 47 (81\%) \\
\hline & Mucosal & $10(18.9 \%)$ & $5(16.1 \%)$ & $9(15.5 \%)$ \\
\hline & Non intact skin & $5(9.4 \%)$ & $3(9.7 \%)$ & $2(3.5 \%)$ \\
\hline \multirow{11}{*}{ Ward } & Total & $53(100 \%)$ & 31 (100\%) & $58(100)$ \\
\hline & Emergency & $7(13.2 \%)$ & $2(6.5 \%)$ & $7(12.1 \%)$ \\
\hline & Surgery & $10(18.9 \%)$ & $8(25.8 \%)$ & $11(19 \%)$ \\
\hline & Orthopedics & $8(15.1 \%)$ & $1(3.2 \%)$ & $5(8.6 \%)$ \\
\hline & Medical & $11(20.8 \%)$ & $5(16.1 \%)$ & $10(17.2 \%)$ \\
\hline & Intensive care & 0 & $1(3.2 \%)$ & $4(6.9 \%)$ \\
\hline & Laboratory & $2(3.8 \%)$ & $2(6.5 \%)$ & $5(8.6 \%)$ \\
\hline & Hemodialysis & $13(24.5 \%)$ & 11 (35.5\%) & $7(12.1 \%)$ \\
\hline & Infectious & 0 & 0 & $5(8.6 \%)$ \\
\hline & Others & $2(3.8 \%)$ & $1(3.2 \%)$ & $4(6.9 \%)$ \\
\hline & Total & $53(100 \%)$ & 31 (100\%) & $58(100)$ \\
\hline \multirow{4}{*}{ Contaminated substance } & Blood & $43(81.1 \%)$ & $23(74.2 \%)$ & $51(87.9 \%)$ \\
\hline & Bloody fluids & $7(13.2 \%)$ & $4(12.9 \%)$ & $3(5.2 \%)$ \\
\hline & Other contaminated substance & $3(5.7 \%)$ & $4(12.9 \%)$ & $4(6.9 \%)$ \\
\hline & Total & $53(100 \%)$ & $31(100 \%)$ & $58(100)$ \\
\hline \multirow{4}{*}{ Type of device } & Injection needle & 27 (65.85\%) & $16(61.5 \%)$ & $36(73.46 \%)$ \\
\hline & Suture needle & $12(29.3 \%)$ & 8 (30.76\%) & $11(22.49 \%)$ \\
\hline & Bistory & $2(4.8 \%)$ & $2(7.6 \%)$ & $2(4.08 \%)$ \\
\hline & Total & $41(100 \%)$ & $26(100 \%)$ & 49 (100) \\
\hline \multirow{10}{*}{ Cause of contact } & Venous puncture & $4(7.5 \%)$ & $4(12.9 \%)$ & $5(8.6 \%)$ \\
\hline & Splashing & $6(11.3 \%)$ & $4(12.9 \%)$ & $9(15.5 \%)$ \\
\hline & Suturing & $11(20.8 \%)$ & $6(19.4 \%)$ & $10(17.2 \%)$ \\
\hline & Recapping & 0 & $3(9.7 \%)$ & $2(3.4 \%)$ \\
\hline & Injection & $12(22.6 \%)$ & $5(16.1 \%)$ & $13(22.4 \%)$ \\
\hline & Sweeping & $12(22.6 \%)$ & $5(16.1 \%)$ & $13(15.5 \%)$ \\
\hline & Surgery & $4(7.5 \%)$ & $2(6.5 \%)$ & $4(6.9 \%)$ \\
\hline & Aspiration & $1(1.9 \%)$ & $1(3.2 \%)$ & $2(3.4 \%)$ \\
\hline & Other causes & $3(5.7 \%)$ & $1(3.2 \%)$ & $4(6.9 \%)$ \\
\hline & Total & $53(100 \%)$ & $31(100 \%)$ & $58(100)$ \\
\hline
\end{tabular}

around the world experience exposures to sharp and cutting tools which result in 1600 cases of infection with HCV, 66,000 HBV infections and 1000 HIV infections. Damages caused by sharp tools are the main source of HCV infections in the way that it accounts for $40 \%$ of all cases of HCV among the HCWs. In addition, $4.4 \%$ of HIV and $37 \%$ of HBV infections among the HCWs are due to the damages caused by sharp tools in occupational exposures [5].

In the present study, 100 cases of occupational exposures were included. In 36 cases of the mentioned 100 subjects, the source was contaminated by more than one virus. Totally, 58, 31 and 53 cases of exposures to HIV, HBV and HCV had occurred. In this study, the highest rate of exposure (around 35\%) was seen among the nurses. A study carried out on 900 HCWs in three hospitals of Tehran in 2005, reported that $26.1 \%$ of the exposed cases were nurses [6]. Other studies in Taiwan and Saudi Arabia have also showed the highest rates of exposure among the nurses (60.6\% and 56.8\%, respectively) $[7,8]$. Since nurses have more frequent contacts with patients, it is not surprising to see the highest rate of exposure among them.

In our study, the most common places of exposure 
Table 3. Evaluation of previous Hepatitis B vaccination and immunity before and after exposure with Hepatitis B Virus.

\begin{tabular}{|c|c|c|}
\hline \multicolumn{2}{|c|}{ Exposure characteristics } & \multirow{2}{*}{$\frac{N(\%)}{25(80.6)}$} \\
\hline \multirow{3}{*}{ History of vaccination } & Yes & \\
\hline & No & $6(19.4)$ \\
\hline & Total & $31(100)$ \\
\hline \multirow{3}{*}{ Number of vaccination } & 1 dose & $4(16)$ \\
\hline & 2 doses & $3(12)$ \\
\hline & 3 doses & $18(72)$ \\
\hline \multirow{4}{*}{$\begin{array}{l}\text { Information about } \\
\text { immunity following } \\
\text { previous vaccination }\end{array}$} & Positive Antibody & $6(19.4)$ \\
\hline & Negative Antibody & $4(12.9)$ \\
\hline & No data & $21(67.7)$ \\
\hline & Total & $31(100)$ \\
\hline \multirow{3}{*}{$\begin{array}{l}\text { Serology at time of } \\
\text { exposure }\end{array}$} & Positive & $11(35.5)$ \\
\hline & Negative & 20 (64.5) \\
\hline & Total & $31(100)$ \\
\hline \multirow{3}{*}{$\begin{array}{l}\text { Serology } 7 \text { months after } \\
\text { exposure }\end{array}$} & Positive & $20(100)$ \\
\hline & Negative & 0 \\
\hline & Total & $20(100)$ \\
\hline
\end{tabular}

were emergency (21\%) and surgical (20\%) wards. In a study from Saudi Arabia, 42.5\% of the exposures were seen in clinical departments and $19.2 \%$ of them were in emergency departments [8]. Another study in Tehran showed the department of internal medicine was the most common place of exposure (23.3\%) [6].

This difference may be due to different clinical procedures being performed in different medical systems and also the type of instruments used. In an emergency setting, less attention is paid to cautionary measures like wearing gloves while taking blood samples or performing invasive diagnostic-therapeutic procedures because of the haste involved, it should be expected to see more cases of exposure in these departments.

In terms of work experience, in the present study, 75\% of the exposures had occurred among the HCWs with less than 5 years of work experience; in other words, less experience means more chance of being exposed. This finding is similar to the results of the studies conducted in Turkey and Saudi Arabia [9,10]. This may be due to the fact that more experience causes people to become more cautious when performing potentially dangerous tasks. Most exposures had occurred during the first two years, because of their inexperience or high workload.

The most common route of exposure in our study was percutaneous exposure (77\%); mostly due to the insertion of the needle stick when taking blood samples or performing similar procedures. Similar results have been found in other studies $[8,11,12]$.

In this study, 31\% of the exposed cases had not worn gloves when they got exposed. In another study, this figure was $38.2 \%$ and in a study in Turkey, it was $28 \%$ $[7,13]$. Knowing that the most common place of exposure was the emergency department, the reason for not wearing gloves might have been haste or the high load of patients to be worked on, which possibly resulted in the temporary shortage of gloves.

In our study, $88.5 \%$ of the HCWs were fully vaccinated (3 doses) while in Egypt, the figure was only $15.8 \%$ [12]. In recent years, the coverage of immunization against $\mathrm{HBV}$ has improved due to the existence of more active infection control committees in hospitals, educational programs held for the HCWs in this regard and more cooperative behaviors of hospital authorities. However, only $44 \%$ of the HCWs of our study knew about their HBsAb serostatus at the time of exposure and were aware of the necessity of being checked for HBsAb after vaccinations.

The main objective of our study was assessing post exposure prophylaxis with antiretroviral drugs in cases exposed to HIV and also vaccination plus HBIG for HBV and their follow up. As for the efficacy of hepatitis $B$ vaccine in occupational exposures, unlike the prevention of fetal infections with HBV, there have been few studies, but the mentioned figure is $90 \%$ [1]. In our study, no cases of positive HBsAg were seen after the prophylaxis. However, our sample size $(n=20)$ was small and we need to assess the efficacy with a larger sample.

In 2002, the numbers of proven and probable cases of HIV following occupational exposures were respectively 106 and 238 throughout the world, and also 26 cases of infection with HIV despite prophylaxis were reported [14]. In 1996, it was suggested that using zidovudine for cases of occupational exposure to HIV may decrease the hazard, and using a combination therapy was also recommended [15]. No certainly successful method for prophylaxis is available and still preventing contacts with blood is the primary method of prevention. HIV can be communicated despite prophylaxis and there have been reports of incomplete combination therapy for preventing its communication among HCWs $[15,16]$. Some studies have shown that 2-drug and 3-drug therapies were efficacious in $79 \%$ and $83 \%$ of the cases, respectively. These figures indicate that 2-drug therapy lowers the risk of infection to $0.06 \%$ and 3-drug therapy reduces the risk to $0.05 \%$. No information is available regarding the comparisons between 2- and 3-drug therapies [4].

In a case-control study (1987-1995) conducted on 665 HCWs who were exposed to these infections without seroconversion, and also the study carried out on $33 \mathrm{HIV}$ 
patients to determine the risk factors of HIV infection, it was shown that using zidovudine decreased the risk of communication in $81 \%$ of the cases (95\% CI $48 \%$ - 94\%) [17]. No information is available on the relevant clinical trials. Considering the low risk of communication following the exposure, we may need thousands of HCWs exposed to this virus in order to assess the efficacy of prophylactic measures [18].

In a study conducted on HCWs exposed to HIV from 1996 to 1998 who had received a prophylactic treatment, no cases of seroconversion were seen among the 306 HCWs who were followed-up for 6 months thereafter [19]. In the study carried out on 380 cases of occupational exposure including 23 cases of HBV, 15 cases of HIV and 12 cases of HCV in India, no cases of infection with these viruses were reported among the exposed HCWs [20]. In our study, no cases of positive HIV were seen. Although this may be due to the prophylaxis, this finding should be considered conservative because of the small sample size of the study.

Hence, considering the fact that according to other studies, there may be a risk of virus communication despite the prophylaxis, it should be recommended that the HCWs observe the principles of occupational safety as the best way of preventing blood borne diseases in dealing with the patients. On the other hand, the vaccination of the HCWs and performing subsequent serological tests to ensure its effect is one of the mainstays of the preventive measures against HBV. On the other hand, establishing a surveillance system for registering the occurrence of occupational hazardous exposures, performing prophylactic measures and following up the exposed is a necessity in hospitals so that the number of exposures and occupational diseases among the HCWs can be decreased.

\section{Limitations \& Suggestions}

Considering the low transmission risk of the viruses following occupational exposure and the small sample size, not observing seroconversion in the personnel studied in our study cannot necessarily be considered as prophylaxis success.

The authors of the article suggest that in order to evaluate the effectiveness of prophylaxis, occupational exposure cases is conducted with a larger sample size in those undergoing prophylaxis or cases who do not receive it regardless of the reason.

\section{Acknowledgements}

This paper is the report of a research project approved and supported by Tehran University of Medical Sciences. The authors thank Dr. Mahdi Aloosh, Dr. Baharak Mehdipour for their Research Assistance and Mrs. Bita
Pourmand for her editing the manuscript. We are indebted to the Research Development Center of Sina Hospital for its support.

\section{REFERENCES}

[1] E. N. Daryani, "Viral and Autoimmune Hepatitis," Taeb, Tehran, 1991, pp. 77-153.

[2] Centers for Disease Control, "Updated U.S. Public Health Service Guidelines for the Management of Occupational Exposures to HBV, HCV, and HIV and Recommendations for Postexposure Prophylaxis,” Morbidity and Mortality Weekly Report, Vol. 29, No. 50(RR-11), 2001, pp. $1-42$.

www.cdc.gov/mmwr/preview/mmwrhtml/rr5011a1.htm

[3] A. K. Sepkowitz, "Nosocomial Hepatitis and Other Infections Transmitted by Blood and Blood Products,” In: G. L. Mandell, J. E. Bennett and R. Dolin, Eds., Principles and Practice of Infectious Diseases, 6th Edition, Churchill Livingstone, Philadelphia, 2005, pp. 3381-3405.

[4] I. V. Bassett, K. A. Freedberg and R. P. Walensky, "Two Drugs or Three? Balancing Efficacy, Toxicity, and Resistance in Postexposure Prophylaxis for Occupational Exposure to HIV," Clinical Infectious Diseases, Vol. 39, No. 3, 2004, pp. 395-401. doi:10.1086/422459

[5] A. Pruss-Ustun, E. Rapiti and Y. Hutin, "Estimation of the Global Burden of Disease Attributable to Contaminated Sharps Injuries among Health-Care Workers," American Journal of Industrial Medicine, Vol. 48, No. 6, 2005, pp. 482-490. doi:10.1002/ajim.20230

[6] A. Hadadi, S. Afhami, M. Karbakhsh and N. Esmailpour, "Occupational Exposure to Body Fluids among Healthcare Workers: A Report from Iran,” Singapore Medical Journal, Vol. 49, No. 6, 2008, pp. 492-496.

[7] W. B. Hsieh, N. C. Chiu, C. M. Lee and F. Y. Huang, "Occupational Blood and Infectious Body Fluid Exposures in a Teaching Hospital: A Three-Year Review," Journal of Microbiology, Immunology and Infection, Vol. 39, No. 4, 2006, pp. 321-327.

[8] S. Jahan, "Epidemiology of Needlestick Injuries among Health Care Workers in a Secondary Care Hospital in Saudi Arabia,” Annals of Saudi Medicine, Vol. 25, No. 3, 2005, pp. 233-238.

[9] Z. A. Memish, M. Almuneef and J. Dillon, "Epidemiology of Needlestick and Sharps Injuries in a Tertiary Care Center in Saudi Arabia,” American Journal of Infection Control, Vol. 30, No. 4, 2002, pp. 234-241. doi:10.1067/mic.2002.118841

[10] A. Azap, O. Ergonul, K. O. Memikoglu, et al., “Occupational Exposure to Blood and Body Fluids among Health Care Workers in Ankara, Turkey," American Journal of Infection Control, Vol. 33, No. 1, 2005, pp. 48-52. doi:10.1016/j.ajic.2004.08.004

[11] W. Phipps, H. H. Wang, M. Yang, J. Burgess, L. Pellico, C. W. Watkins, G. P. He and A. Williams, "Risk of Medical Sharps Injuries among Chinese Nurses," American Journal of Infection Control, Vol. 30, No. 5, 2002, pp. 277-282. doi:10.1067/mic.2002.122435 
[12] M. Talaat, A. Kandeel, W. El-Shoubary, C. Bodenschatz, I. Khairy, S. Oun and F. J. Mahoney, "Occupational Exposure to Needle Stick Injuries and Hepatitis B Vaccination Coverage among Health Care Workers in Egypt," American Journal of Infection Control, Vol. 31, No. 8, 2003, pp. 469-474. doi:10.1016/j.ajic.2003.03.003

[13] E. M. Jochimsen, "Failures of Zidovudine Postexposure Prophylaxis,” American Journal of Medicine, Vol. 102, No. 5B, 1997, pp. 52-55.

[14] S. Tomkins and F. Ncube, "Occupationally Acquired HIV: International Reports to December 2002," Eurosurveillance, Vol. 10, No. 3, 2005, Article ID: E050310.2.

[15] Centers for Disease Control and Prevention, "Provisional Public Health Service Recommendation for Chemoprophylaxis after Occupational Exposure to HIV," Morbidity and Mortality Weekly Report, Vol. 45, No. 22, 1996, pp. 468-480.

http://www.cdc.gov/mmwr/preview/mmwrhtml/0004220 $0 . h t m$

[16] A. N. Do, C. A. Ciesielski, R. P. Metler, T. A. Hammett, J. Li and P. L. Fleming, "Occupationally Acquired Human Immunodeficiency Virus (HIV) Infection: National Case Surveillance Data during 20 Years of the HIV Epidemic in the United States," Infection Control and Hospital Epidemiology, Vol. 24, No. 2, 2003, pp. 86-96. doi:10.1086/502178

[17] D. M. Cardo, D. H. Culver, C. A. Ciesielski, P. U. Srivastava, R. Marcus, D. Abiteboul, J. Heptonstall, G. Ip- polito, F. Lot, P. S. McKibben and D. M. Bell, for Centers for Disease Control and Prevention Needlestick Surveillance Group, “A Case-Control Study of HIV Seroconversion in Health Care Workers after Percutaneous Exposure,” New England Journal of Medicine, Vol. 337, No. 21, 1997, pp. 1485-1490. doi:10.1056/NEJM199711203372101

[18] J. I. Tokars, R. Marcus, D. H. Culver, C. A. Schable, P. S. McKibben, C. I. Bandea and D. M. Bell, for The CDC Cooperative Needlestick Surveillance Group, "Surveillance of HIV Infection and Zidovudine Use among Health Care Workers after Occupational Exposure to HIV-Infected Blood,” Annals of Internal Medicine, Vol. 118, No. 12, 1993, pp. 913-919. doi:10.7326/0003-4819-118-12-199306150-00001

[19] S. A. Wang, A. L. Panlilio, P. A. Doi, A. D. White, M. Stek Jr. and A. Saah, "Experience of Healthcare Workers Taking Postexposure Prophylaxis after Occupational HIV Exposures: Findings of the HIV Postexposure Prophylaxis Registry," Infection Control and Hospital Epidemiology, Vol. 21, No. 12, 2000, pp. 780-785. doi:10.1086/501736

[20] A. Mehta, C. Rodrigues, S. Ghag, P. Bavi, S. Shenai and F. Dastur, "Needlestick Injuries in a Tertiary Care Centre in Mumbai, India," Journal of Hospital Infection, Vol. 60, No. 4, 2005, pp. 368-373. doi:10.1016/j.jhin.2004.12.015 